\title{
Una defensa ética de lo teatral. Rousseau o el sobrino de Rameau
}

\author{
An Ethical Defence of Theatricality: \\ Rousseau or Rameau's Nephew
}

\author{
Guillermo De Eugenio PÉREZ
}

Universidad Carlos III de Madrid

Resumen. En este trabajo se discuten dos modelos opuestos de construcción de la identidad a partir de la contraposición que hace el filósofo Bernard Williams de las figuras de Rousseau y el sobrino de Rameau de Diderot. Frente a la concepción representacional de la identidad como copia o proyección de un ser interior, se propone una noción performativa de la personalidad basada en la espontaneidad y la multiplicidad como fuentes del sujeto contemporáneo. En el trasfondo de esta reflexión se encuentra la hipótesis de que ambos métodos de producción ética de la identidad personal responden a concepciones estéticas profundamente enraizadas, una más próxima al modelo pictórico de copia de un original y la otra, teatral, basada en la importancia de la interpretación en los procesos de creación.

Palabras clave: Autenticidad, Representación, Performatividad, Rousseau, Identidad.

Esta reflexión se desarrolla en torno a dos escenas; ambas suceden en la segunda mitad del siglo XVIII, en Francia. La primera tiene lugar en 1771, en un salón de los de antes de la Revolución, el del conde Egmont. Allí, Jean Jacques Rousseau lee en voz alta sus Memorias recién terminadas,
ABSTRACT. In this paper there are two opposite models for identity to be discussed, departing from the comparison made by philosopher Bernard Williams between the figures of Rousseau and Rameau's nephew. Against the representational conception of an identity as the copy or proyection of an inner self, we propose a more performative notion of personality, conceived in terms of spontaneity and multiplicity as sources of the contemporary subject. In the background of this reflection there is the hypothesis that both methods of producing personal identity respond to aesthetic conceptions that are deeply rooted. One of them is closer to the pictorial model of a copy from an original, and the other, theatrical, is based in the importance of performance on creative processes.

Key words: Autenticity, Representation, Performativity, Rousseau, Identity.

ante un público entre aburrido y escandalizado por la falta de pudor del filósofo. En un extremo, el esfuerzo del hombre virtuoso por sincerarse, en un monólogo, confesando sus pecados; en el otro, la actitud hostil del auditorio. Transparencia y obstáculo. La segunda escena es más des- 
enfadada, y la fecha más incierta: M. Diderot, también filósofo, acude al café de la Regencia para estar "solo con sus pensamientos". Allí se topa con un antiguo conocido, personaje infame del París de aquellos días: un pedigüeño, un mísero bufón, pero también un hombre libre. El diálogo entre ambos surge y se propaga con facilidad. De un lado tenemos el monólogo, la confesión, la pureza, el intento de fijar algo; del otro, el diálogo, el contagio de ideas, la inestabilidad.

La relación entre la filosofía y el teatro siempre ha sido problemática. Aunque hace ya mucho tiempo que se admite la idea de que la vida es como un inmenso teatro, en el que nosotros mismos representaríamos a la vez el rol del actor y el del espectador, esta idea contiene siempre un cierto tono derogatorio. Hablar de la teatralidad del mundo es siempre, o casi siempre, hacer una crítica de su falsedad, donde lo mundano es equiparado a lo superficial. Las ideas que se discuten en este trabajo se fundamentan en una premisa básica que afecta directamente al núcleo de la metáfora del theatrum mundi, a saber, que cultivar la propia personalidad se ha convertido en objeto de un "arte de sí". Ya no basta con ser veraz, en el sentido en que los antiguos estoicos consideraban la persona, el yo en tanto que sujeto moral. El yo moderno posee una personalidad que debe visibilizarse; hay que resultar verosímil en el papel que se interpreta. Lo que me gustaría abordar en los siguientes párrafos son algunos modos posibles de concebir esa verosimilitud en su vínculo con el ideal de autenticidad que fundamenta la imagen de una persona (su personalidad) y los conflictos que ello plantea.
Lo que nos presenta Rousseau, principalmente en sus Confesiones, así como en las Reflexiones del paseante solitario, y lo que representa el lui en El sobrino de Rameau de Diderot son dos posturas enfrentadas, dos formas contrapuestas de concebir la identidad. La identidad como esencia de lo que intenta permanecer igual a sí mismo y la identidad como actividad, es decir, como diferencia generadora de mismidad, producen dos tipos distintos de relación entre la mímesis y la personalidad. En el relato que Rousseau hace de su propio pasado se dan cita tanto el autor como el personaje, y la identidad se manifiesta como narración de sí ante los otros: una puesta a prueba de la propia excelencia ante un auditorio muy exigente y poco proclive a la simpatía. El planteamiento narrativo de Diderot, más relajado, se abre a partir de un diálogo cordial y aparentemente casual sobre la posibilidad de configurar un yo mediante distintos fragmentos, retales y destrezas puestas en juego en el presente. Pero más que un conflicto entre un yo histórico y un sujeto que vive en el presente, lo que tenemos son dos teorías estéticas que informan a los sujetos. Aquí, la vieja concepción clásica de la mímesis como representación de una esencia o idea, con su dualidad original/simulacro. Allí, una estética teatral más que pictórica, la creación a partir de la acción, la imitación como puesta en escena de lo ya visto u oído, la fuerza paródica del gesto y la magia de la improvisación.

\section{Anhelos de transparencia}

En la obra de Bernard Williams, Verdady veracidad, encontramos un análisis sobre las condiciones en que el acceso a la "ver- 
dad" como fin del conocimiento se encuentra estrechamente vinculado a la virtud epistémica de la precisión y la virtud ética de la Sinceridad o veracidad. Por ejemplo, un relato ficticio puede no ser verdadero pero ser veraz, en el sentido de que transmite un contenido que está íntimamente relacionado con una verdad profunda, aunque lo que se cuenta nunca sucediera, o al menos no como se relata. Esta es la verdad de los mitos. Estas tres formas (precisión, verdad, veracidad), aunque aparecen siempre juntas, varían notablemente en su percepción de unas culturas a otras, e incluso se dan casos de compleja convivencia entre percepciones aparentemente incompatibles. El noble Odiseo no es menos admirado para los griegos de la antigüedad clásica por ser un mentiroso, sino al contrario, esta habilidad forma parte de su virtud específica, su areté ${ }^{1}$. Podemos enriquecer aún más el análisis de Williams añadiéndole una dimensión política a la veracidad. La voluntad de decir la verdad, de ponerse uno mismo en el discurso, ha sido también recuperada por Michel Foucault, bajo el término de "parresía", como es sobradamente conocido, en sus últimos cursos del Collège de France 2 . Podría considerarse que la admiración de los griegos en, pongamos, el siglo $\mathrm{V}$ a.C. por el personaje homérico de la Odisea no les impedía comprender hasta qué punto la parresía era una virtud fundamental en el espacio público del ágora. Ahora bien, cuando se trata de decir la verdad sobre uno mismo, el problema de la veracidad tomó un rumbo muy particular en la cultura occidental, ya que en un momento histórico preciso, en pleno proceso de formación de la subjetividad romántica, esta cuestión de la veracidad va a ser sustituida por, o mejor, a devenir el problema de la "autenticidad".

En el capítulo octavo de su obra, Williams aborda la cuestión de la coincidencia entre identidad y personalidad de un individuo contraponiendo el modelo de autenticidad que encontramos en la obra autobiográfica de Rousseau con uno de los personajes más célebres de Diderot, el sobrino de Rameau, en su obra homónima. Ambos son presentados como casos paradigmáticos de la relación del sujeto consigo mismo y con los otros en términos de veracidad y autenticidad. Según Williams, y también Jean Starobinski ${ }^{3}$, el principal problema de Rousseau en este sentido consistiría en asumir que la relación del sujeto con su propio yo es transparente: Rousseau identificaba ese yo capaz de conocerse perfectamente a sí mismo y la necesidad ética de manifestarse "tal cual es", de confesar, con el núcleo de toda virtud. Por lo tanto, los fracasos a la hora de darse a conocer ante los demás (su opacidad) sólo podían ser una consecuencia del empeño de los otros por malinterpretarlo, su negativa a concederle el reconocimiento; y, sólo de manera subsidiaria, el efecto de cierta incompetencia social por parte del propio Rousseau.

Este profundo anhelo de autenticidad, unido a la exigencia de una transparencia que se presenta como absoluta y, al mismo tiempo, está ubicada en el ámbito del discurso, que aparece como sede de la autenticidad (mientras que la conducta narrada se presenta como ocasión de todo tipo de malentendidos), producen un conflicto irresoluble en el seno de su proyecto 
de identidad. Este conflicto es claramente perceptible en los primeros capítulos de las Confesiones, en el contraste entre la declaración de intenciones y la presentación de sí que hace el autor y la vileza que demuestra en el episodio juvenil del robo de la cinta, complicado con una mentira que hará que una chica inocente pague por las consecuencias de un acto cometido por el joven Jean-Jacques. Constantemente, y en particular hacia los últimos capítulos, Rousseau se presenta como una víctima, un chivo expiatorio perseguido por la iniquidad de los hombres de la buena sociedad. Su culpa: ser demasiado ingenuo, demasiado puro para este mundo. No obstante, esta inocencia no se manifiesta por la ausencia de gestos mezquinos, torpes o rencorosos, que pueblan las Confesiones, sino por el sentido de culpa insoportable que le persigue y le obliga a confesar. Según la concepción de una ética situacional que, como decía Deleuze ${ }^{4}$, proyectaba Rousseau, la situación de encontrarse en sociedad lo convertía en un ser inauténtico, mientras que la situación de encontrarse frente a frente consigo mismo, en ese espejo que son las confesiones y la escritura, lo devuelven a su auténtico ser. De alguna forma el hombre Rousseau se siente obligado a sufrir por los desaguisados cometidos por los personajes que, en tanto que actor del teatro del mundo, se ha visto obligado a interpretar. La sinceridad y la espontaneidad en el relato de sí vienen de este modo a sustituir, como virtud fundamental, a la conducta virtuosa:

...Y resolví formar con [Las Confesiones] una obra única, de una veracidad sin ejemplo, a fin de que a lo menos una vez pudiera verse a un hombre tal como es interiormente...
Yo sabía que me presentaba a los ojos del público bajo un aspecto tan poco parecido al mío, $\mathrm{y}$ a veces tan disforme, que, a pesar de lo malo, de que no quería callarme nada, no podía menos de ganar aún, mostrándome tal cual soy. ${ }^{5}$

Sólo mediante el distanciamiento y la mediación de la escritura, mediante el aislamiento reflexivo, puede Rousseau exponerse a sí mismo ante los otros sans recherche, sans gêne. Si la virtud de la autenticidad y la veracidad, quedan del lado de la esencia que se expresa en el relato biográfico, la vileza pasa al terreno de la causalidad, de la conducta, de las situaciones. Podría pensarse que la autotransparencia de Rousseau no es, a menudo, otra cosa más que autoengaño o mala fe en el sentido sartreano, ya que se empeña sistemáticamente en externalizar el mal expulsándolo fuera de sí, ya sea atribuyéndolo a los otros o bien identificando sus malas acciones como "mera" conducta, como algo circunstancial, inesencial $^{6}$. Este gesto de repudio de una parte del propio relato como "mera conducta" sería una forma de conciliar lo que León Festinger denominara "disonancia cognitiva", contradicción interna en el circuito de ideas, creencias y emociones de un sujeto $^{7}$. En este sentido parece apropiado traer a colación en apoyo de este argumento la paradoja enunciada por Hume a propósito de Rousseau: “creo que se propone en serio esbozar su propio retrato con sus colores verdaderos: pero, a la vez, creo que nadie se conoce menos a sí mismo" 8

Sin embargo, creo que lo fundamental de su razonamiento acerca de la veracidad se encuentra en las relaciones interpersonales. Frente al otro, el yo se 
"aliena", no puede no actuar de acuerdo con lo que cree que el otro espera, sabe que actúa delante de un público. Frente a sí mismo, sin embargo, se encuentra delante de un tribunal que por su forma de dramatización propia favorece la actitud confesional, hace posible la veracidad. Jean-Jaques Rousseau, juez y acusado en el tribunal de su conciencia. Igual que el buen mentiroso debe ser capaz de engañarse un poco a sí mismo, quien quiere ser auténtico debe antes aprender a desnudarse ante sí mismo.

Otro rasgo del pensamiento de Rousseau a tener en cuenta en este caso es su rechazo virulento de lo teatral $y$, en particular, de la teatralidad como estilo de vida, que podemos encontrar tanto en sus escritos teóricos, en particular la Carta a $D^{\prime} A$ lembert, como en la novela Julie o la nueva Eloisa ${ }^{9}$. Alguien como el actor, familiarizado con las técnicas del fingimiento, adolece de un yo fragmentado y debe por fuerza acabar perdiendo de vista su auténtico ser. El actor, tanto el profesional como el que finge en la vida diaria, acaban por extraviarse en el juego de espejos de la actuación. El modelo de autenticidad rousseauniano presume muchas cosas: sinceridad, virtud, coherencia, constancia, conocimiento de las propias motivaciones... pero sobre todo presupone un yo homogéneo con manifestaciones heterogéneas, algunas de las cuales no le pertenecen realmente. Así la bondad quedaría definida en los términos de una unidad interna y virtuosa del sujeto consigo mismo. En última instancia, eso significa que solo puede conquistarse la autenticidad fuera del trato con los otros, ya que los otros nos hacen actuar de manera diferente a como realmente somos.

El espacio público, para Rousseau, implica una automatización de las conductas que aleja irremediablemente a las personas de su auténtico yo. La sociedad de los salones, por ejemplo, espanta a Saint-Préux (protagonista de La Nueva Eloísa) por la cualidad impersonal de sus actores, la falta de atributos intrínsecos de sus personalidades, su intercambiabilidad, su automatización. En la sociedad los hombres no son más que simulacros de sí mismos:

Así, los hombres con los que se quiere hablar no son con los que se conversa; los sentimientos no salen de sus corazones, las luces no son las de su mente, los discursos no representan sus ideas; sólo vemos en ellos sus rostros, y uno está en una reunión de sociedad casi como delante de un cuadro en movimiento [ $\mathrm{ta}$ bleau vivant], en el que el apacible espectador es el único que se mueve por sí mismo. [...] Hasta ahora he visto muchas máscaras: ¿cuándo veré los verdaderos rostros de los hombres? ${ }^{10}$

Por fortuna, Saint-Préux regresa a tiempo de París para ir a refugiarse en su reducto en las montañas, en compañía de unas pocas y escogidas almas gemelas. Por desgracia, Rousseau no tuvo tanta suerte y su retiro fue tomando, a medida que se adentraba en la vejez, los tintes de inestabilidad del paria vagabundo. Diderot responderá medio en broma a este ideal en su obra El hijo natural, diciendo, en clara alusión a la decisión de Rousseau de irse a vivir en soledad al campo, que "sólo el hombre malvado vive solo". Lo que parece estar señalando Diderot a Rousseau en esa alusión, que fue interpretada como un ataque gratuito, es que sólo a través de los otros 
nos vemos como realmente somos. De esta manera, el enciclopedista hace alusión a las identidades colectivas y a la configuración social de la identidad individual, a nuestra necesidad de reconocimiento por parte de los otros que es tan esencial para la constitución del propio yo.

Frente al modelo rousseauniano en conflicto irresoluble consigo mismo y con los otros, Williams propone tomar la obra de Diderot El sobrino de Rameau, como una alternativa aceptable. Esta obra se plantea como un diálogo, un juego entre dos conciencias, moi et lui, donde el "yo" es un trasunto del propio Diderot que busca cierta coherencia burguesa en sus planteamientos estéticos y morales, mientras que "él" es el sobrino de un célebre músico que encarna la conciencia descarnada de la modernidad. La sinceridad de este último personaje es de un tipo no condicionado por las convenciones sociales y más coherente que la de Rousseau. Rameau es "auténtico" y honesto, pero no virtuoso. Su capacidad de verse a sí mismo tal y como es no deriva del examen introspectivo, sino que más bien responde a un tipo de sinceridad que no excluye la propia abyección, sino que la manifiesta. Es un bufón, un servidor displicente que se adapta al requerimiento de la audiencia: irreflexivo y desinhibido, adula y engaña a cada momento, pero no tiene ningún problema en confesarlo abiertamente. $\mathrm{Su}$ forma de ser auténtico y de conocerse a sí mismo como conoce a los demás tiene más que ver con la espontaneidad que con la adecuación a un ideal.

Según la tesis de Williams, la inconstancia natural de la persona de la que el sobrino da muestra, es "estabilizada" en la mayoría de los individuos mediante los efectos socializadores del contacto con otras personas. Lo que forma el "carácter" de una persona, más allá de su temperamento natural, es esta educación que consiste en tratar a los demás como si sus reacciones $y$ formas de ser fueran predecibles. Esta exigencia de fiabilidad de las conductas anclada en la estabilidad de un yo se ha ido volviendo una tarea cada vez más difícil a medida que nos aproximamos al momento actual, debido a la fragmentación del sujeto. Ya Hume había afirmado la multiplicidad del yo en función del flujo de representaciones que integran la conciencia, y en el siglo XIX, Hegel en su Fenomenología del Espíritu, identificará al sobrino de Rameau con la conciencia desgarrada de ese sujeto en la modernidad, en una relación dialéctica con la conciencia burguesa que pretende mantener unidos los pedazos, que es el moi del diálogo ${ }^{11}$.

Curiosamente, la expectativa de fiabilidad guiada por las prácticas de socialización (o, dicho de otro modo, la "teatralización de la vida cotidiana") no resulta completamente defraudada por la mutabilidad compulsiva de un sujeto del tipo del sobrino de Rameau. Al fin y al cabo, él se adapta a la audiencia; incluso en su perpetuo cambio resulta predecible: nunca sincero si tiene interés en ser falso, nunca falso si tiene interés en ser sincero. Tampoco se engaña a sí mismo respecto de su propia forma de ser, ni, por tanto, engaña a los otros. El modelo de sinceridad que ofrece el sobrino de Rameau permite a Williams plantear varias preguntas realmente interesantes: ¿qué sucede si finalmente no aprendemos a proyectar una 
imagen estable del yo? ¿pueden convivir en un mismo individuo creencias dispares, contradictorias, pero igualmente sinceras? ¿es más sincera una creencia cuanto más espontánea? ¿cuál es la función de los deseos en todo esto? ¿significa esto que muchos deseos divergentes en una persona implican múltiples personalidades?

Aquí nuestra línea de argumentación se separa de estos interrogantes planteados por Williams para volver sobre el análisis de la figura del sobrino de Rameau y ver si puede ser iluminado bajo una luz ligeramente distinta, que nos permita saber algo más sobre lo que significa poseer un "arte de sí", fabricar una personalidad. Explicaré esto con algo más de detalle: la relación del sujeto con el entorno social, con los otros, en términos de un proceso del que emerge la personalidad puede ser concebido según tres modelos fundamentales; uno en el que el sujeto se proyecta o proyecta una imagen de sí que reciben los demás con mayor o menor distorsión (este parece ser el modelo desde el que opera la narrativa rousseauniana). Este es el modelo del rostro y la máscara, que podemos llamar representacional. Un segundo modelo, digamos conductual propone que el flujo transcurre en sentido inverso, que son los demás los que nos moldean, los que nos hacen ser como somos. Aquí estaríamos más cerca de la concepción que tiene Diderot de la constitución de la subjetividad, al menos según la lectura de Williams ${ }^{12}$. Un tercer modelo, que es el que pretendo proponer en aquí, implica una síntesis de los dos anteriores: no pueden comprenderse correctamente los procesos de gestación y desarrollo de la identidad moderna, compleja, a no ser que se tenga en cuenta que es el doble flujo, del yo a los otros y de la sociedad al sujeto, en términos de una narración en la que ese sujeto trata de dar cuenta de sí, de dar sentido y dotarse de una personalidad, pero siempre ante la mirada de la comunidad.

El presente trabajo se distancia del planteamiento de Williams en que no se hace un énfasis tan marcado en el vínculo entre los aspectos cognitivos y su relación con las virtudes éticas, en el contexto de las prácticas de constitución de la identidad. El giro principal consiste en descargar el peso de las nociones de verdad y veracidad y trasladar el foco hacia la noción de performatividad. Este nuevo enfoque no nos dirá si una determinada expresión del sujeto es más o menos "verdadera" que otra, no más de lo que la propia valoración subjetiva del individuo puede hacerlo, porque no confía en la lógica de la representación. No hay un grado cero, un original o un patrón sobre el que medir la autenticidad de las representaciones. De hecho, ni siquiera hay representaciones, sino sólo distintas manifestaciones que constituyen la identidad en lugar de reflejarla.

El problema que se plantea aquí no tiene que ver con decir la verdad o mentir, aunque el fingimiento y la mentira sí tienen un papel importante a la hora de explicar los procesos implicados en la constitución de un yo escindido en dos, un yo interno o íntimo (verdadero) y otro externo o social (falso). La alternativa que nos ofrece el sobrino de Rameau como personaje absolutamente moderno consiste en poner de manifiesto la importancia de la performatividad frente a las exi- 
gencias de autenticidad de la lógica platónica de la mímesis $y$, en última instancia, de la dicotomía mentira/verdad a la que, de alguna forma, Williams continúa aferándose en su análisis. El sobrino nos hace plantearnos la cuestión de la autenticidad, no desde el punto de vista de la veracidad del sujeto, de su adaptación a un ideal o a un original; sino de su actualidad, de su capacidad para manifestarse a cada momento presentándose ante nosotros y ante los otros mediante ciertas prácticas, gestuales y discursivas, que configuran su aparición e inspiran un tipo de reconocimiento u otro. En última instancia, si se trata aquí en alguna manera de la "verdad", no es una verdad que aparece como oculta, velada, o que sea revelada, develada, sino de una verdad que se delata a sí misma en los gestos, y de un sujeto que no necesita ser idéntico a sí mismo para ser auténtico.

\section{Enter trickster}

La escena comienza con la entrada del filósofo (moi) en un café, adonde lo ha conducido su intención de "observar mucho, hablar poco y escuchar lo menos posible". Los cafés eran, en esta época, lugares donde personas de todo rango y posición se encontraban para hablar libremente e intercambiar todo tipo de chismes. Pero cuando se sienta con la intención de observar a los jugadores de ajedrez, otro parroquiano lo aborda, haciendo imposible la introyección del filósofo y arrastrándolo sin remisión a un diálogo con el otro (lui) en el que el yo va dejándose seducir poco a poco. En realidad, se trata de un relato sin trama, en el que el filósofo respetable y su interlocutor hablan un poco de la vida en general, y mucho del arte, mientras va aflorando la autobiografía del personaje de Rameau, junto con otras anécdotas del París prerrevolucionario.

Nada es más distinto de él que él mismo $^{13}$, dice Diderot, y el sobrino lo confirma a su vez: "todo lo que sé es que a mí me gustaría en el fondo ser otro, para ver si me tocaba por casualidad ser un genio, un gran hombre"14. Frustrado, perplejo, exclama en otro momento " $\mathrm{Q}$ Que el diablo me lleve si se quién soy en realidad!" El sobrino no sabe, a ciencia cierta, qué es; de hecho, es un actor de la vida cotidiana. En medio de la conversación se enciende y comienza a representar a velocidad vertiginosa todos los caracteres de las óperas que ha representado, cuya música sabe de memoria. Dentro de su mediocridad, el sobrino es un auténtico virtuoso de la interpretación dramática y musical, un artista de la parodia. La expresión de su rostro varía adoptando las expresiones que los manuales de Della Porta, Le Brun o Descartes describen en sus tratados de fisiognomía. He aquí una imitación sin mímesis, en la que la adopción de las distintas figuras no tiene como referente la naturaleza, sino el arte, y no se orienta hacia la expresión de una autenticidad interna, sino que se deja llevar, como poseído, por el capricho del instante. El sobrino está como loco, saisi d'une aliénation d'esprit.

Además de su cercanía con la locura y su carácter proteico, la otra característica del sobrino es su derelicción, el abandono en el que vive sumido. Vive consumiendo las sobras de los banquetes de los podero- 
sos. En este momento acaba de ser expulsado de la casa de Mme. Hus, una actriz famosa del momento, probablemente por haberse excedido en su representación, ya que él es un "original", uno de esos que "rompen la fastidiosa uniformidad de nuestra educación, nuestras convenciones sociales $[. .$.$] y restituyen a cada cual una$ porción de individualidad personal"15. Él es quien desenmascara a los pillos y pone de manifiesto que todos habitamos en una farsa: es descarado como un filósofo cínico o una prostituta, y le gusta frecuentar la compañía de los otros. Como Diógenes, escupe a la cara de sus anfitriones su propia hipocresía reflejada como en un espejo, pero no rehúye la compañía de sus semejantes, sino que la necesita para poner en marcha su performance. Al desenmascarar a los demás pone de manifiesto que el espacio social se ha convertido en una danza en el vacío. Es el movimiento que hace girar el mundo; un ritmo al que incluso el rey debe someterse: la postura que imprime en el cuerpo la complacencia, el deseo de agradar a los otros, de someterse, de asimilarse.

El sobrino de Rameau se compara a sí mismo con los bufones que, como en $E l$ rey Lear, ponen de manifiesto la locura del monarca. Asume abiertamente su naturaleza múltiple, se complace en exhibirse como un personaje ridículo, pero con una condición: sólo será ridículo cuando él quiera, no cuando los otros se lo ordenen. De esta manera se aferra al último reducto de dignidad humana, se reconoce a sí mismo como un ser, quizás no digno de respeto, pero sí acreedor de cierta libertad y movilidad. En cualquier caso es poseedor de un derecho de autodeterminación al que no está dispuesto a renunciar y mediante el cual se rebela contra los lazos de dependencia que lo deshumanizan. Por eso se venga burlándose de sus anfitriones. Puestos a deshumanizarse, se dice, dejadme hacerlo como y cuando me plazca:

Cada cual tiene [su dignidad]; acepto olvidar la mía, pero voluntariamente, no por orden de otro. Sólo porque se me diga "arrástrate", ¿estoy obligado a arrastrarme? Es la andadura del gusano y también la mía; la seguimos ambos cuando nos dejan en paz, pero nos erguimos cuando nos pisan la cola. ${ }^{16}$

No sabe quién es, y sin embargo se conoce mejor que nadie, porque sabe reconocerse. El es dolorosamente consciente de su profunda abyección, como si fuera una herida profunda en su costado, o un abismo abierto en su ser: "Soy un ignorante, un loco, un perezoso, un impertinente... cada uno de esos epítetos me valía una sonrisa, una caricia, una patada, en la mesa una buena tajada, fuera de la mesa una libertad que yo me tomaba sin mayores consecuencias, porque yo soy un inconsecuente"17. Es la verdad profunda del sobrino, una verdad que se encuentra en la superficie. Se sabe a sí mismo mediocre e insatisfecho, y en el fondo le gustaría ser como su próspero tío, como el respetable filósofo con el que departe, como Lulli, como todos aquellos que, a diferencia de él, han tenido éxito. Sin embargo, esa insatisfacción, unida a su franqueza al hablar de sus propias motivaciones sin embellecerlas ni ocultarlas, es la única dignidad que conserva. Pero es una forma de dignidad irreductible, porque la única vileza con la que no transige es el autoengaño. La mayor parte de los hombres llevan una máscara ante sí mismos y ante 
los demás, creen ser una cosa pero en realidad son otra muy distinta, y acaban por identificarse con el papel a fuerza de interpretarlo. Rameau interpreta tantos roles a lo largo del día que no puede permitirse la ilusión de una identidad confortablemente homogénea. Él afirma su identidad y su originalidad reivindicando una abyección que actúa como catalizador de la toma de conciencia y, al mismo tiempo, invierte la relación: ;O stercus pretiosum! ${ }^{18}$ (joh precioso excremento!). En cierto sentido, su postura trasciende la mera materialidad de las circunstancias en que se encuentra como arrojado. Al fin y al cabo, lo ab-iectum, lo que está abajo, es también el sub-iectum, lo que subyace, el núcleo de una identidad bajo las conductas que la ponen de manifiesto.

Este personaje, que vive en un universo de máscaras, es incapaz de encontrar una que le cobije: “¡Hacerse una máscara que se le parezca! Esa máscara, sobre todo, me trastorna... ¡La máscara, la máscara! Daría uno de mis dedos por haber encontrado la máscara."19 ¿Cuál es esta máscara por la que el sobrino se hubiera dejado mutilar? Se trata de la habilidad del hombre de mundo para presentarse ante los otros como alguien virtuoso en el sentido aristotélico; es decir, como alguien siempre igual a sí mismo, cuyas emociones, deseos y acciones resultan coherentes. Ahora, en este punto de la exposición, desearía introducir un pequeño golpe de efecto, una peripecia dentro del relato contrastado de estos dos personajes ejemplares. Esta máscara, que el personaje de Diderot se confiesa incapaz de hallar, fue encontrada (o mejor dicho, producida) y usada durante algún tiempo por quien menos cabría sospechar, el propio Rousseau.
A menudo se han tratado de sacar a relucir las supuestas constantes contradicciones en la obra de Rousseau, sobre todo cuando habla de sí mismo. Sin embargo, creo que es más acertado decir que, más que contradictorio, el sujeto que Rousseau nos representa es complejo y ambivalente como el mismo deseo. En un momento dado de su vida, nos dice el filósofo, consiguió convertirse en la expresión pura de sí mismo, incluso en medio de la mistificación de los salones:

Hasta entonces yo había sido bueno; desde aquel momento fui virtuoso, o a lo menos apasionado por la virtud. Esta pasión había empezado en mi cabeza, mas había pasado a mi corazón. El más noble orgullo germinó en los restos de la desarraigada vanidad. No simulé nada: fui efectivamente lo que parecí, y, lo menos por espacio de cuatro años que duró esta efervescencia, nada grande y bello es capaz de tomar asiento en el corazón humano, de que no fuese capaz el mío quedando entre el cielo y yo. He ahí de dónde nació mi súbita elocuencia, he ahí cómo se derramó en mis primeros libros este fuego celestial que me abrasa y de que no se había perdido la menor chispa durante cuarenta años, porque todavía no estaba encendido.

Yo estaba verdaderamente transformado; mis amigos y mis conocidos no me reconocían ya; no era éste aquel hombre tímido y más bien vergonzoso que modesto, que no se atrevía a presentarse, ni a hablar, a quien desconcertaba la menor chanza, a quien hacía sonrojar la mirada de una mujer. Audaz, valeroso, intrépido, llevaba a todas partes una seguridad tanto más firme en cuanto era sencilla y residía más en mi alma que en mi exterior. ${ }^{20}$

Esta forma exacerbada de sí, este cáustico fustigador de los vicios humanos que acabó convirtiéndose en un personaje más 
de los poblados tableaux parisinos, tampoco es todavía el "auténtico" Rousseau. Rousseau se presenta aquí como la máscara perfecta, la que reproduce lo mejor posible el interior; sin embargo, al abandonar París y el espectáculo de sus vicios, se nos cuenta, regresa a su estado original, más dulce, aunque menos sublime. Vuelve a ser "miedoso, complaciente, tímido, en una palabra, el mismo Juan-Jacobo que había sido antes". No todas las prevenciones de Rousseau contra la teatralidad son fruto de sus amargos fracasos; algunas lo son del agridulce recuerdo de sus grandes triunfos en sociedad, de la época en que consiguió conquistar la máscara sublime de la virtud y llevarla con orgullo por todo París. Por un lado, Rousseau actúa como el viejo Diógenes o el sobrino de Rameau, señalando a la sociedad corrupta sus vicios; por otro, su concepción externalista y puritana del mal le obliga a no presentarse como un ser imperfecto. Por eso Rousseau aparece tan a menudo, visto a través de los ojos de los otros, como un personaje ridículo y pomposo. Entonces no había comprendido aún que para denunciar la estupidez y la vileza de los demás uno debe estar dispuesto a mostrar su propia abyección. Esto le permite mostrar una imagen titánica, una inmensa mole de virtud, pero le convierte también en una caricatura de sí mismo.

El sobrino de Rameau hubiera querido también encontrar "la" máscara, pero no la tiene; se encuentra fuera de la lógica de las máscaras. La teatralidad que practica es otra, distinta de la que se ordena por la lógica del rostro verdadero y la máscara mentirosa. De hecho, la subvierte. Es demasiado autoconsciente para ese juego, su actitud es demasiado cínica, demasiado irónica, demasiado lúcida para que no lo traicione una nota paródica en cada una de sus actuaciones. El sobrino de Rameau es demasiado plástico, su rostro cambia tan deprisa y de manera tan abierta que no puede ser confundido con una máscara; pero no es un hipócrita, ya que no engaña a nadie. En el último momento, se desvincula del esencialismo de la máscara y el rostro para mostrarnos otro tipo de imagen: la cara embadurnada del cómico, del clown, que no oculta ni desvela, sino que realiza la dimensión ridícula de los personajes de este teatro del mundo:

En lo que me decía había muchas cosas que se piensan, a las cuales uno ajusta su conducta; pero que no se dicen. Esa es la diferencia más marcada entre mi hombre y la mayoría de los que nos rodean. Confesaba sus vicios, que los demás también tienen; pero él no era hipócrita. No era ni más ni menos abominable que los otros; era, simplemente, más franco, más consecuente; y a veces más profundo en su depravación. $^{21}$

El sobrino de Rameau es un actor, un tipo de agente cuya identidad está definida por su interpretación en un escenario de máscaras sociales; pero dentro de esa categoría, nuestro personaje corresponde a un tipo concreto de actor: es un trickster. Este término, tomado de la antropología y de la crítica cultural, corresponde a un arquetipo $^{22}$, una figura, una especie de personaje que se caracteriza por su posición excéntrica con respecto a la comunidad. Es un outsider del que todos desconfían, pero puede también llegar a convertirse en héroe fundador. $\mathrm{Su}$ forma de actuar consiste en romper las convenciones sociales, trasgrediendo nor- 
mas y tabúes mediante su discurso y sus actos. Esto lo convierte, por supuesto, en un personaje egoísta, amoral, pero al mismo tiempo apasionado, sensible, astuto; rasgos que inevitablemente lo hacen simpático para quien escucha el relato de sus peripecias (en este caso el filósofo Diderot y también el lector). Haciendo uso del humor, el trickster se convierte en un actor según la fórmula diderotiana ${ }^{23}$, uno que consigue distanciarse tanto de su propia actuación como de las representaciones que los demás tratan de proyectar, sin perder ni un ápice de su espontaneidad. El sobrino de Rameau es uno, probablemente el más grande de los tricksters de la modernidad, pues altera sus límites y plantea la cuestión central de la identidad: ¿en qué consiste ser una persona?

Se ha dicho que de este personaje que en él Diderot pone de manifiesto la incivilidad y la pérdida de los valores de la deferencia en el Antiguo Régimen ${ }^{24}$, pero en realidad, hace mucho más que eso. Este simpático caradura, que también tiene su dimensión trágica (o al menos patética) no se limita a trasgredir la etiqueta: deconstruye literalmente la realidad en la que viven los personajes, mostrando el vacío que se impone en el lugar donde deberían estar los pilares que sustentan la conducta sociable. El reconocimiento de lo extraño, no solo en los demás, sino también dentro de sí como algo intrínseco, la renuncia a externalizarlo como hacía Rousseau, es la principal (y seguramente la única) virtud del sobrino. Esta actitud lo pone fuera de la lógica de la máscara y el rostro: él es todo cara, o todo máscara. La diferencia en su caso se esfuma como el maquillaje lo hace sobre el rostro de un actor. Grita que el rey está desnudo y se desnuda él mismo al hacerlo. Esto no es, se dirá, totalmente nuevo; la sátira había sido practicada ya en el siglo anterior por autores como La Bruyère, al que por cierto se cita en el texto. Pero lo que los moralistas del siglo anterior nunca hicieron fue poner en práctica sus enseñanzas bajo la forma de la destrucción sistemática y performativa, encarnada, de aquello que criticaban mediante la parodia y la pantomima, usando el mundo como un teatro y el propio cuerpo como instrumento. Esto es lo que convierte al sobrino de Rameau en un trickster, y en un héroe (o anti-héroe) del mundo moderno.

\section{Representación y performatividad}

Uno de los grandes aciertos de Bernard Williams en su análisis consiste en contraponer la figura del sobrino de Rameau y de Rousseau como dos modelos antagónicos de la concepción de la autenticidad en el siglo XVIII, una oposición enriquecedora que dice mucho sobre la andadura de eso que llamamos el sujeto en los tres últimos siglos de cultura occidental. Parte de lo que se ha propuesto en este trabajo trata de hacer notar que, si inclinamos demasiado la balanza del lado de la veracidad tal como la concibe Rousseau, corremos el riesgo de pasar por alto cuestiones relevantes para el estudio de la subjetividad. Principalmente, que la formación de la persona como un "arte de sí" implica esquemas mentales que tienen que ver con la forma de interpretación de distintas disciplinas o prácticas del yo. Uno puede hacerse a sí mismo según el modelo de la pintura (representación) o de las artes escénicas (performatividad) y ambas elecciones producen efectos bien distintos.

Lo que nos propone Rousseau es un 
modelo de virtud basado en la identidad entre el sujeto interno y su manifestación, cuya premisa necesaria es la autotransparencia del sujeto, eso mismo que el inconsciente freudiano hace altamente improbable. La persona atrapada en el modo rousseauniano de la representación se afana en parecerse a su original solo para descubrir, como los protagonistas de la película de Kiarostami, Copia certificada (2010), que en el mundo todo son copias de copias, y que el que alcanza la felicidad no es el que da con el original, sino quien encuentra la versión que más le va. Esto es lo que hace de la ética una cuestión eminentemente práctica, una práctica de sí. La ascética no es siempre un movimiento hacia el autoperfeccionamiento, sino que a veces el asceta se ve obligado a reconocerse en su propia abyección, en su teatralidad intrínseca.

Lo que nos propone el sobrino de Rameau (que no debe ser confundido con la opinión personal del propio Diderot) es una personalidad que, lejos de renunciar a la coherencia, se constituye como un arte de la interpretación improvisada de sí mismo a cada instante, y no la copia servil de un modelo único. Sigue en esto el tipo de acción artística que implican el teatro y la música. El hecho de que el sobrino aparezca como un sujeto fracturado es, según la interpretación que aquí se propone, algo circunstancial. Depende de las condiciones de vida extremas en que se encuentra: su vulnerabilidad en un contexto específico, su marginalidad social. Solo hablamos de sujetos fracturados cuando fracasan; si consiguen dar un sentido a sus vidas, aunque sea manteniendo la multiplicidad de manifestaciones, posi- blemente divergentes, entonces hablamos de un "sujeto complejo". Si para Williams su principal virtud consistía en el rechazo frontal de la mala fe rousseauniana, debemos añadirle otra ventaja a este modelo. Su relato es especialmente iluminador porque indica ya la senda que conduce a los sujetos complejos de la contemporaneidad, como atestiguan su capacidad performativa, su creatividad y su sensibilidad cultivadas con descuidada perseverancia.

Por otro lado, no es necesario suponer que la actitud de este iconoclasta de las normas sociales no representa mejor de lo que lo hacía el personaje de Rousseau la actitud contemporánea frente a la propia personalidad. Podríamos describir esta actitud más bien como una postura ambivalente entre ambos modelos, que es lo que caracteriza la actitud reflexiva de los sujetos. En última instancia, el modelo de construcción de una personalidad que encontramos en el personaje de Diderot tiene la ventaja de no dejarse atrapar nunca, de absorber toda la disparidad que genera, de sus disposiciones cambiantes, sin dejar de reconocerse a sí mismo, aunque de una forma extrañada. Pero un sujeto desencantado en un mundo desencantado tiene siempre la necesidad de soñar el regreso a la infancia, o a un yo bueno y puro escondido en el interior de cada ser humano, y por eso invoca, una y otra vez, al fantasma de Rousseau. 


\section{BIBLIOGRAFÍA}

Cranston, M., The Solitary Self: Jean-Jacques Rousseau in Exile and Adversity, Chicago U.P., 1997.

Deleuze, G., En medio de Spinoza, Cactus, Buenos Aires, 2008.

Diderot, D., El sobrino de Rameau, Cátedra, Madrid, 1985.

Diderot, D., Paradoxe sur le comèdien, Gallimard, Paris, 1994.

Festinger, L., A theory of cognitive dissonance, Stanford U.P., 1957.

Foucault, M., L'herméneutique du sujet. Cours au Collège de France. 19811982, Gallimard, Paris, 2001.

Hegel, G.W.F., Fenomenología del Espíritu, Abada, 2010.

Hume, D., Tratado de la naturaleza humana, Tecnos, Madrid, 2005.

Hynes, W. J. y Doty. W. (eds.), Mythical Trickster Figures: contours, contexts and criticism, University of Alabama Press, Tuscaloosa, 1997.

Jung, C.G., "On the Psychology of the
Trickster-Figure", en Four Archetipes: Mother, Rebirth, Spirit, Trickster, Princeton U. P., 1969.

Mortier, R., L'originalité. Une nouvelle catégorie esthétique au siècle des Lumières, Droz, Genève, 1982.

Rousseau, J.-J., Confesiones, Planeta, Barcelona, 1993.

Rousseau, J.-J., Oeuvres Complètes, Gallimard, Paris, 1995.

Rousseau, J.-J., Julie o la nueva Eloisa, Akal, Madrid, 2007.

Saint-Armand, P., "La crise de la déférence à la fin de l'Ancien Régime. Insolence et Incivilité chez Diderot", en Communications. La déférence 69 (2000), pp. 61-69.

Sartre, J.-P., El ser y la nada, Losada, Buenos Aires, 2006.

Starobinski, J., Jean-Jacques Rousseau. La transparence et l'obstacle, Gallimard, Paris, 1971.

Williams, B., Verdad y veracidad, Tusquets, Barcelona, 2006.

\section{NOTAS}

${ }^{1}$ Williams, B., Verdad y veracidad, Tusquets, Barcelona, 2006. pp. 22, 264.

${ }^{2}$ Foucault, M., L herméneutique du sujet. Cours au Collège de France. 1981-1982, Gallimard, Paris, 2001, pp. 355-374.

${ }^{3}$ Starobinski, J., Jean-Jacques Rousseau. La transparence et l'obstacle, Paris, Gallimard, 1971.

${ }^{4}$ Deleuze, G., En medio de Spinoza, Cactus, Buenos Aires, 2008, p. 129

${ }^{5}$ Rousseau, J.-J., Confesiones, Planeta, Barcelona, 1993, p. 542.

${ }^{6}$ Sartre, J.-P. El ser y la nada, Losada, Buenos Aires, 2006, pp. 43-55.

${ }^{7}$ Festinger, L., A theory of cognitive dissonance, Stanford U.P., Stanford, 1957, pp. 1-9.

${ }^{8}$ Cranston, M., The Solitary Self: Jean-Jacques Rousseau in Exile and Adversity. Chicago U.P., Chicago, 1997, p. 160.
${ }^{9}$ La matriz netamente platónica de este prejuicio contra los actores, los poetas y, en términos más generales, contra las formas perversas de la mímesis, es particularmente evidente en un pequeño ensayo de Rousseau, Sobre la imitación teatral (Rousseau, J.-J., Oeuvres Complètes, Gallimard, Paris, 1995, vol. V, pp. 1207 y ss.).

${ }^{10}$ Rousseau, J.-J. Julie o la nueva Eloisa, Akal, Madrid, 2007, p. 267. Nótese en esta frase las resonancias de San Pablo, quien dice, de manera muy similar, "Ahora vemos por un espejo y oscuramente, pero entonces veremos cara a cara. Ahora conozco sólo parcialmente, pero entonces conoceré como soy conocido" (Corintios I, 13:12). Si el modelo estilístico de la confesión se toma prestado de San Agustín y la crítica a la mímesis de Platón, parece bastante acertado suponer que el tipo de conocimiento de sí al que aspira Rousseau, basado en la autenticidad, es en parte una forma secularizada de la reflexividad paulina. 
${ }^{11}$ Hume, D., Tratado de la naturaleza humana, Libro I, Parte IV, Sección VI; Hegel, G.W.F., Fenomenología del Espíritu, VI, B I a.

12 "Diderot [...] establece una dimensión social en la construcción de las creencias, de las actitudes e incluso de los deseos. Éstos son los materiales de la idiosincrasia, y la lección que extraemos es que para ser alguien necesitamos al otro." Williams, B., op.cit., p. 195.

${ }^{13}$ Diderot, D., El sobrino de Rameau, Cátedra, Madrid, 1985., p. 68.

${ }^{14}$ Ibid., p. 79.

${ }^{15}$ Ibid., p. 47. Para la definición del término originel en el francés del siglo XVIII vid. Mortier, R., L'originalité. Une nouvelle catégorie esthétique au siècle des Lumières, Droz, , Genève,1982, p. 157.

${ }^{16}$ Ibid.., pp. 107-108.

${ }^{17}$ Ibid., p. 82.

${ }^{18}$ Ibid., p. 88.
${ }^{19}$ Ibid., p. 113.

${ }^{20}$ Rousseau, J.-J., Confesiones, Planeta, Barcelona, 1993, p. 438.

${ }^{21}$ Diderot, op.cit, p. 149.

${ }^{22}$ Jung, C.G., "On the Psychology of the TricksterFigure”, en Four Archetipes: Mother, Rebirth, Spirit, Trickster, Princeton U. P., Princeton, 1969, pp. $153-$ 152. Como obra de referencia para los estudios sobre la figura del trickster, vid. Hynes, W. J. y Doty. W. (eds.), Mythical Trickster Figures: contours, contexts and criticism, University of Alabama Press, Tuscaloosa, 1997.

${ }^{23}$ Diderot, D., Paradoxe sur le comèdien, Gallimard, Paris, 1994.

${ }^{24}$ Saint-Armand, P., "La crise de la déférence à la fin de l'Ancien Régime. Insolence et Incivilité chez Diderot", en Communications. La déférence., n 69, 2000, pp. 61-69. 